\title{
Understanding breast cancer screening-past, present, and future
}

\author{
Jacqueline CM Sitt *, CY Lui, Lorraine HY Sinn, Julian CY Fong
}

This article was published on $6 \mathrm{Apr}$ 2018 at www.hkmj.org.

\section{A B S T R A C T}

This article provides an up-to-date overview of breast cancer mammography screening and briefly discusses its history, controversies, current guidelines, practices across Asia, and future directions. An emphasis is made on shared decision-making-instead of giving just a 'yes' or 'no' answer to patients, the focus should be on providing sufficient information about the pros and cons of screening to help women make a personal, informed choice. Frontline experts, including breast surgeons, oncologists, breast radiologists, and their representative professional associations should all participate in guideline panels, with the goal of improving cancer detection, reducing mortality, and improving patient outcome.

\section{Hong Kong Med J 2018;24:166-74}

DOI: $10.12809 / \mathrm{hkmj} 177123$

JCM Sitt *, MB, BS, FHKCR

CY Lui, MB, ChB, FHKCR

LHY Sinn, MB, BS, FHKCR

JCY Fong, MB, BS, FHKCR

Hong Kong Women's Imaging Limited, Suite 319, 3/F, Central Building, Central, Hong Kong

* Corresponding author: jacquelinesitt@gmail.com

\section{Introduction}

This article provides an up-to-date overview of breast cancer mammography screening and briefly discusses its history, controversies, current guidelines, practices across Asia, and future directions. An emphasis is made on shared decisionmaking - instead of giving just a 'yes' or 'no' answer to patients, the focus should be on providing sufficient information about the pros and cons of screening to help women make a personal, informed choice.

\section{Goals and advantages of breast cancer screening}

The goal of mammographic screening (and other breast-cancer screening tests) is to detect breast cancer earlier than it would otherwise manifest clinically, when it is less likely to have spread. Data clearly show that detection of breast cancers at smaller sizes and lower (earlier) stages is associated with better patient outcomes, lower morbidity, and reduced breast cancer deaths. ${ }^{1}$ Reduced morbidity is likely to be related to feasibility of breast conservation and hence less extensive surgery, fewer associated complications such as lymphoedema, less chemotherapy, and hence fewer adverse effects. ${ }^{2}$ Other benefits of diagnosing screen-detected cancers at an earlier stage also include a lower cost of treatment and consequent reduced financial burden on health care resources. ${ }^{3}$

\section{Current guidelines}

The Table summarises the mammography guidelines from selected nations. ${ }^{4,5}$ In common, all organisations emphasise that the benefits of screening outweigh the harm at all ages. ${ }^{3,6}$ They all endorse informed decision-making and the importance of informing women about both benefits and limitations of screening. However, there remain legitimate concerns about guideline differences, including the complexity of the guidelines; weak adherence to creating opportunities for informed decision-making; unreadiness of referring clinicians to discuss benefits, limitations, and harm associated with screening; and the lack of reminder systems, which results in weaker adherence to recommended screening intervals. Despite these concerns, it is widely accepted that high adherence to even the least aggressive guidelines will save more lives than the current weak adherence to regular screening programmes. $^{4}$

\section{Current scientific evidence to support screening}

Randomised controlled trials (RCTs) have been the gold standard for proving that early detection with mammography decreases mortality from breast cancer. Since the very first screening RCT performed in New York in the 1960s, there have been eight prospective RCTs and numerous subsequent metaanalyses published. Most well-executed RCTs demonstrated a $20 \%$ to $30 \%$ decrease in mortality from breast cancer when women were invited for screening. These results laid a solid foundation for population-based screening programmes worldwide. ${ }^{1,7,8}$ 
Subsequent studies that generated data from population-based screening programmes have provided further evidence of the benefits of screening mammography. The true benefit reported (in terms of mortality reduction) ranged from $38 \%$ to $49 \%$, even higher than that shown by RCTs. This difference demonstrates that service screening studies measure the direct effect of screening on women who actually underwent mammography, and not just those who were invited to undergo mammography (as opposed to the methodology of RCTs). Service screening studies also tend to measure the effect of more recent screening practices that have benefited from improved mammography technology, better breast positioning techniques, and improved interpretive skills. ${ }^{1,9}$

\section{Understanding screening controversy and 'mammographic wars'}

\section{了解乳癌篩查：過去、現在、將來 薛靜雯、呂振英、冼凱忻、方俊仁}

本文提供乳癌乳房X線照相篩查的最新概況, 並簡要討論其歷史、爭 議、當前指引方針、亞洲各地的實踐以及未來方向。有關指引的重點 在於 $「$ 共同決策」，而非為患者提供 $「$ 是」或 $「$ 否」的答案，亦應側 重於提供有關篩查利弊的充分資訊, 以協助婦女作出個人和知情的選 擇。前線醫護人員, 包括乳房外科、腫瘤科和乳腺放射科專家, 以及 其專業協會代表都應參與指引專家小組，以改善癌症檢測、降低死亡 率和改善患者預後為目標。

\section{The Canadian National Breast Screening Study: root of all controversies}

One exception to the RCTs that reported unfavourable results of mammographic screening

TABLE. Summary of mammography guidelines from selected nations ${ }^{4,5}$

\begin{tabular}{|c|c|c|c|c|}
\hline Country and organisation & $\begin{array}{l}\text { Age to start } \\
\text { screening, } y\end{array}$ & $\begin{array}{l}\text { Age to stop } \\
\text { screening, y }\end{array}$ & $\begin{array}{l}\text { Frequency of } \\
\text { assessment }\end{array}$ & Comments \\
\hline \multicolumn{5}{|l|}{ United States } \\
\hline $\begin{array}{l}\text { United States Preventive Services Task } \\
\text { Force }\end{array}$ & 50 & 74 & $\begin{array}{l}\text { Every } 2 \text { y (for women } \\
\text { at average-risk of } \\
\text { breast cancer) }\end{array}$ & $\begin{array}{l}\text { Screening for women aged } 40-49 \text { y is } \\
\text { a "Grade C" recommendation (offer or } \\
\text { provide this service for selected patients } \\
\text { depending on individual circumstances) }\end{array}$ \\
\hline $\begin{array}{l}\text { American Cancer Society } \\
\text { American Society of Breast Surgeons } \\
\text { American Society of Surgical Oncology }\end{array}$ & 45 & $\begin{array}{l}\text { As appropriate based } \\
\text { on life expectancy }\end{array}$ & $\begin{array}{l}\text { Annually then } \\
\text { biennially at age } 55 \text { y } \\
\text { and older }\end{array}$ & $\begin{array}{l}\text { Recommend continuing screening as } \\
\text { long as the individual is in good health } \\
\text { and has a life expectancy exceeding } 10 \mathrm{y}\end{array}$ \\
\hline $\begin{array}{l}\text { American College of Obstetricians and } \\
\text { Gynecologists }\end{array}$ & $\begin{array}{l}\text { 40; no later } \\
\text { than } 50 \text { (if } \\
\text { does not start } \\
\text { at } 40 \text { ) }\end{array}$ & $\begin{array}{l}\text { As appropriate based } \\
\text { on life expectancy }\end{array}$ & Every $1-2$ y & $\begin{array}{l}\text { (1) Emphasise shared decision-making } \\
\text { with discussion of benefits and harms of } \\
\text { screening; incorporate patient's values } \\
\text { and preferences; } \\
\text { (2) Suggest discussing cessation of } \\
\text { screening with physician starting at age } \\
75 \text { y }\end{array}$ \\
\hline $\begin{array}{l}\text { American College of Radiology/ } \\
\text { Society of Breast Imaging }\end{array}$ & 40 & $\begin{array}{l}\text { As appropriate based } \\
\text { on life expectancy }\end{array}$ & Annually & $\begin{array}{l}\text { Suggest continue screening as long as } \\
\text { life expectancy exceeds } 5-7 \mathrm{y}\end{array}$ \\
\hline $\begin{array}{l}\text { National Comprehensive Cancer } \\
\text { Network }\end{array}$ & 40 & $\begin{array}{l}\text { Stopping age } \\
\text { depends on co- } \\
\text { morbidity and } \\
\text { therapeutic decisions }\end{array}$ & Annually & \\
\hline
\end{tabular}

\section{Canada}

Canadian Task Force on Preventive Health Care

\section{Sweden}

Socialstyrelsen

40

74

United Kingdom

National Health Service

Every $2-3$ y

Not applicable

\section{The Netherlands}

National Breast Screening Programme

\section{Australia}

Royal Australian College of General Practitioners

$50 \quad 74 \quad$ Every $2-3$ y $\quad$ Not applicable

$74 \quad$ Every 18-24 mo Not applicable

$50 \quad 75 \quad$ Biennially $\quad$ Not applicable

$50 \quad 74 \quad$ Biennially $\quad$ Not applicable

$50 \quad 70 \quad$ Triennially $\quad$ Expanding the age range of invited

$50 \quad 70 \quad$ Triennially Expanding the age range of invited women to $47-73 \mathrm{y}$ is being considered 
was the Canadian National Breast Screening Study (CNBSS). It was conducted between 1980 and 1985, and was divided into two parts. The first CNBSS included approximately 50000 volunteer women aged 40 to 49 years, and determined the mortality benefit in the experimental group, who were assigned to annual screening mammography plus clinical breast examination (CBE) versus the control group who received usual care. ${ }^{10}$ The second CNBSS had almost 40000 volunteer women aged 50 to 59 years, and compared the benefit of annual mammography plus $\mathrm{CBE}$ with that of yearly $\mathrm{CBE}$ alone. ${ }^{11}$

From the time the results were first published in 1992 and again after follow-up in 2000, 2002, and 2014, the CNBSS has been controversial, because it is the only RCT to have reported no decrease in mortality associated with an invitation to screening. The study also claimed a $22 \%$ overdiagnosis of screendetected invasive cancer, increasing to up to $35 \%$ when cases of ductal carcinoma in situ (DCIS) were included. ${ }^{12-14}$ However, the credibility and scientific value of the CNBSS study have been repeatedly questioned in peer-reviewed publications. ${ }^{15-19}$ Most criticisms of this study are related to vulnerabilities and shortcomings in its execution, including flaws in the randomisation process, lack of statistical power, non-generalisable results, poor quality imaging, suboptimal mammographic image acquisition and interpretation by untrained personnel, and inconsistent thresholds for interpretation.

The flaws in the randomisation process principally arose from three areas. First, unlike all other RCTs, potential participants in the Canadian trials initially underwent a careful physical examination. Second, women with positive findings on physical examination, including palpable lumps, skin or nipple retraction, and even palpable axillary adenopathy, were not excluded from this 'screening' trial. ${ }^{18}$ Finally, randomisation was unblinded and decentralised. Because almost $80 \%$ of women with advanced palpable cancers were assigned to the screening arm in the first round of the study, there has been speculation that concerned clinicians did not follow the randomisation process, but rather assigned some symptomatic women to the study group so that they would undergo mammography. ${ }^{19}$ Whether the imbalance was due to intentional tampering or occurred by chance alone, the net effect was the same-namely, a failure to produce two equal cohorts of patients for comparison.

The CNBSS was also criticised at the time of the trial for poor quality mammography, even compared with mammographic imaging of that era. ${ }^{15,20}$ To reduce radiation dose, mammography for the trial was performed without the benefit of scatter-reducing grids despite their routine use and availability. Standard imaging for much of the trial used a straight lateral view, not a mediolateral- oblique view, which images more tissue. The combination of poor quality imaging and the investigators' resistance to taking corrective action led two advisors' resignation in protest. In addition, technologists who participated in the trial received no special training in performing mammography. Radiologists new to mammography also received no training in interpretation. ${ }^{18}$ There was also a lack of immediate follow-up after recommendations for biopsy had been made. Overall, about $25 \%$ of the recommended biopsies were ultimately not performed. ${ }^{18}$

The CNBSS trials are an excellent example of the need to carefully consider all facets of a largescale screening trial before accepting its results as scientifically valid. The numerous design and execution flaws described above explain in large part why the results of the CNBSS are dramatically different from those of all other RCTs. Ultimately, on the basis of the methodology of the CNBSS, the World Health Organization excluded those results when analysing the breast-screening data in the International Agency for Research on Cancer report. ${ }^{21}$

\section{Controversial meta-analysis results from the Nordic Cochrane Centre}

The greatest debate on the value of breast screening arose after the publication of a highly controversial but frequently quoted meta-analysis by Gotzsche (a medical statistician and director of the Nordic Cochrane Centre) and Olsen in The Lancet in 2000. Their study concluded that there was no benefit of mortality reduction by screening, after discarding six of eight RCTs because they deemed the randomisation to be "inadequate". The only two RCTs included in their analysis showed no benefit, including the Malmo trial and the notorious CNBSS. ${ }^{7,22}$

Gotzsche and Olsen's critique and methodology have caused much controversy and, in turn, have been criticised heavily by leading expert breast imagers, public health clinicians, and professional bodies such as the Society of Breast Imaging., ${ }^{7,23-27}$ Gotzsche and Olsen's use of quoted figures from cancer registries rather than actual patient data, their selective approach to studies, and in particular the ignoring of the flaws of the CNBSS, have received the harshest criticism. Many experts have commented that Gotzsche and Olsen overstated the limitations of most of the well-executed RCTs, thereby reflecting a "contextfree" application of guidelines in a way that did not address the real issues relevant to the effectiveness of mammographic screening. Moreover, Gotzsche and Olsen's recommendation to abandon screening altogether has hampered collaborative efforts to improve breast cancer detection and control. ${ }^{27}$ 


\section{Swiss Medical Board's decision to stop population-based screening in 2014}

In February 2014, the Swiss Medical Board attempted to overturn the widespread practice of mammography screening in Switzerland by stating that new systematic mammography screening programmes should not be introduced, irrespective of women's age, and recommended that existing programmes should be discontinued. Their main argument was that the absolute risk reduction in breast cancer mortality was low and that the adverse consequences of screening (false-positive test results, overdiagnosis, overtreatment, and high costs and expense of follow-up tests and procedures) were substantial. ${ }^{28,29}$

The Swiss Medical Board's attempt initiated a new phase of heated arguments and debate about the benefits of screening. Expert breast cancer clinicians in both the United States and Europe (including leading cancer associations in Switzerland) rejected their report. One criticism was that the Swiss Medical Board relied heavily on the controversial work by Gotzsche and Olsen and again quoted data from the flawed CNBSS. Another criticism that attracted great attention was the questionable "expert panels" of the board: they included a medical ethicist, a clinical epidemiologist, a clinical pharmacologist, an oncology surgeon, a nurse scientist, a lawyer, and a health economist. Frontline breast imagers, with expertise in diagnosing breast diseases, were excluded from the review panels because of a "conflict of interest".28,29

The Swiss Medical Board did not adequately consider the fact that assessment of the balance between benefit and harm involves a value judgement that each woman should make only after she is fully informed about the strengths and weaknesses of screening mammography. They also disregarded the extensive literature in support of screening mammography (RCTs and population service screening studies), making their attempt at stopping national mammography screening unjustified.

\section{Potential risks of screening overstated}

Commonly mentioned potential harms of screening include false-positive mammograms, recall for additional imaging, a false-positive biopsy, missed breast cancer, radiation dose, patient anxiety, and, above all, overdiagnosis.

Overdiagnosis is defined as the detection (and subsequent actions taken) of a cancer by screening that would not have progressed to become symptomatic in a woman's lifetime. ${ }^{1}$ The estimation of overdiagnosis is complex, highly debated, and very difficult to measure. ${ }^{3}$ Reported figures range widely, from $0 \%$ to $50 \%$, vary greatly in terms of methodological rigour, and testify to the inexact nature of most mathematical models. ${ }^{30-34}$ When appropriate adjustments for temporal trends, risk factors, and lead time are considered, the level of overdiagnosis should be low, within the range of $0 \%$ to $10 \%{ }^{32}$ Importantly, a recent study of over 5 million women (aged 50-64 years) screened by the United Kingdom's National Health Service showed that there was a significant negative association between the detection of DCIS at screening and invasive interval cancers. In that study, Duffy and colleagues analysed the data from four consecutive screen years and the 36-month outcome after each relevant screen. For every three screen-detected cases of DCIS, there was one less interval case of invasive cancer over the next 3 years. They agreed that the policy on detection and treatment of DCIS is worthwhile and can prevent subsequent invasive cancers. ${ }^{35}$

The effect of screening on heightening a patient's anxiety has also been long questioned by critics, but the magnitude of the effect may have been over-exaggerated. In a survey of over 1200 women with a 6-question anxiety scale to understand the short-term and long-term impact of a recall examination, women involved in the digital mammographic imaging screening trial demonstrated only a transient, limited increase in anxiety after a false-positive mammogram compared with those with a negative mammogram, and there was no difference between the two groups' intention to undergo mammography again in the subsequent 2 years. ${ }^{36}$ Schwartz et al reported that $96 \%$ of American women who received a false-positive mammography report were glad that they underwent the test and remained supportive of screening. ${ }^{37}$ Most women agreed that the anxiety, inconvenience, and the few image-guided needle biopsies using local anaesthesia associated with a recall from screening, were minor compared with dying of breast cancer. ${ }^{38}$

To summarise, papers citing a high rate of overdiagnosis in screening (in the magnitude of $20 \%$ or higher) and claiming that false-positives are a significant cause of patient anxiety are believed by most experts to be overstating the case.

\section{Harms of not screening underestimated}

Although it is important to discuss all aspects of screening asymptomatic women (including potential harm), the harm of not attending screening is underestimated and not discussed. For instance, women who do not attend screening have significantly larger tumours, a higher stage at diagnosis, poorer overall and disease-specific survival, and higher costs of treatment. ${ }^{39}$ It has been estimated that the cost of treating advanced metastatic breast cancer exceeds US\$ 250000 per patient, and the 
average cost of treating advanced cancer in the first year after diagnosis is almost double that of early cancers, mainly owing to the difference in costs of chemotherapy. ${ }^{3,40}$ The cost of treatment and lost productivity each year will far exceed the cost of annual screening and, additionally, do not include the indirect value of the lives saved (as a productive member of workforce). ${ }^{1}$

\section{Situation in Asia}

\section{Rising breast cancer incidence: a universal phenomenon among Asian women}

The incidence of breast cancer continues to increase worldwide. It remains highest in the United States and Europe, but has been increasing substantially in Asian countries over the past three decades. ${ }^{41}$ Studies that compare invasive breast cancer data from Asia with those from the United States over a 20-year period have shown that female breast cancer incidence among Asian and Western populations is more similar than expected. ${ }^{42}$ The incidence of female breast cancer in China will continue to rise, and is expected to exceed 100 per 100000 women by 2021 , giving a total of 2.5 million cases. ${ }^{43}$

According to GLOBOCAN 2012 of the International Agency for Research on Cancer, the specialised cancer research agency of the World Health Organization, almost a quarter (24\%) of all breast cancers were diagnosed within the AsiaPacific region, with the greatest number occurring in China (46\%). ${ }^{44}$ The age-standardised incidence rate was highest among Taiwanese (65.9 per 100 000), followed by Singaporeans, South Koreans, and Japanese. ${ }^{44}$ In a multiracial country such as Singapore, Chinese women have been noted to have a significantly higher risk of developing breast cancer than Malays and Indians. ${ }^{45}$

The disease burden in Hong Kong is no different. Locally, the age-standardised incidence rate was 58.8 per 100000 in 2015, with over 3900 new cases per year. ${ }^{46}$ A study of the local trend in female breast cancer incidence from 1973 to 1999 by the University of Hong Kong showed a significant yearly increase of an average of $3.6 \%$; the increase was most marked and continued to accelerate in the younger age-groups. It was speculated that such trend changes were related to Westernisation of lifestyle. ${ }^{47}$ All these data indicate that the disease burden in Hong Kong is increasing and comparable to that of all other civilised Asian countries and cities.

\section{Breast screening programmes in Asia}

Breast screening services in Asian countries and cities are highly variable: some have advanced nationwide screening programmes and others have less developed programmes. ${ }^{48}$ South Korea and
Taiwan are both well recognised for their experience in running such programmes, the former having the highest intake rate and the latter being the most well-structured.

South Korea places a very strong emphasis on screening for cancer control in general. Its national health service offers mammography and CBE every 2 years to women aged 40 or older, and at no cost to the $50 \%$ of people with the lowest incomes. Their programme is popular and widely accepted by the general public, and achieved an uptake of as high as $66 \%$ in 2014. Benefits of downstaging from screening were also observed. However, South Korea encountered a problem of potential overdiagnosis, with a noticeably higher false-positive rate when compared with other places.

Taiwan's health authorities have been recognised for rolling-out well-organised and wellresourced screening programmes, with good support from a local randomised controlled trial showing a reduction in mortality by $40 \%$ with mammography screening. ${ }^{49}$ Since 2004 , their health service has provided free breast screening to women aged 50 to 69 years, expanded in 2010 to those aged 40 to 49 years. By 2015, about $40 \%$ of the target population participated in screening. It is believed that the cause of the suboptimal participation rate was not due to capacity or outreach, but rather the Taiwanese public's values and attitude. Nonetheless, with more resources being directed to public education and motivation, Taiwan's health authorities are pushing their goal to $60 \%$ by 2018 .

The experience of screening programmes in Singapore and Japan is more equivocal. Despite having sufficient scientific evidence to support their role in reducing mortality and reducing invasive cancer incidence, the participation rate has remained lower than expected, mostly owing to cultural barriers and paradigms, or a lack of central governing. Singapore established its national, population-wide screening programme (BreastScreen Singapore) in 2002 and now covers women aged 40 to 69 years. The participation rate has been noted to plateau at $40 \%$ since 2010 , short of the target of $70 \%$. The health promotion board believes that apart from cultural issues, costs (as screening is paid by an individual's medical insurance account) constitute the greatest barrier to uptake.

The study of population-based screening in Japan has been complex, with scattered data owing to the lack of a single national organisation for monitoring. The participation rate remains lower than in other comparable Asian countries in the past century, again likely because of cultural paradigms. Despite these barriers, in the past decade, Japanese health officials have started designing their own methods and protocols for screening, particularly targeting the higher incidence of cancer among 
younger women (aged 40-49 years) and the large proportion of patients with dense breasts. After the launch of government-funded screening programmes, a clinical trial that started in 2007 (Japan Strategic Anti-cancer Randomised Trial, JSTART) of over 70000 women undergoing adjunctive ultrasonography to supplement mammography for screening showed an increased sensitivity and detection rate for early preclinical cancers. ${ }^{41}$

In China, there is no nationwide screening programme for breast cancer. A mammographic screening programme was attempted in 2005 but was abandoned because of lack of funding and concerns about false-positive diagnoses. Despite these barriers, national guidelines established in 2007 recommend annual mammography for women aged 40 to 49 years, and every 1 to 2 years for those aged 50 to 69 years. In a Beijing study of 1.46 million women (aged 35 to 59 years) who underwent screening by ultrasonography from 2009 to 2011, the cancer detection rate was 48.0 per 100000 , including 440 cases at early stage that constituted $69.7 \%$ of cases detected. The detection rate was lower than anticipated, maybe in part owing to the young age of the screened group and omission of mammography as a screening tool. Subsequently, a second-generation screening programme was initiated in 2012, after modification of the screening methods, cohort size (6 million), and target population that included women aged 35 to 64 years. The new screening procedures include parallel CBE and breast ultrasonography; women with suspicious findings from either examination are recommended to undergo mammographic imaging. ${ }^{50}$ Although the design of this screening protocol deviates from the standard practice of other countries, we believe that the programme will bring more research data and experience, and eventually lead to more comprehensive guidelines and consensus on a screening approach in China.

\section{Breast-screening programmes in Hong Kong: room for development}

The awareness of breast cancer and acceptance of screening in Hong Kong is growing, but is still inadequate. According to the latest Breast Cancer Registry Report No 8 (2016), which covers 13453 breast cancer patients diagnosed from 2006 onwards, the mean and median age of patients at diagnosis was 52.6 and 51.3 years, respectively, and about two-thirds of patients were aged 40 to 59 years. The screening habits among these patients were poor, with over $60 \%$ never having undergone mammography screening before their cancer diagnosis. ${ }^{51}$

Although to date there has been no population-based screening for women in Hong Kong, opportunistic screening has long been practised in the private sector. The largest voluntary self-financed and self-referred opportunistic screening programme is run by the Tung Wah Group of Hospitals. In a retrospective review of their performance from 1998 to 2002 involving over 46600 screening mammograms, a breast cancer detection rate of five cases per 1000 population was noted, which was comparable to the detection rate of Western screening programmes at that time..$^{52}$

Regarding the input of expertise and quality assurance, the Hong Kong College of Radiologists issued their mammographic statement in 2006 (latest revision in 2015). ${ }^{53}$ Quoting desirable goals recommended by the United Kingdom and United States as a reference the statement sets specific benchmarks for standards of mammographic machines, quality of screening mammograms, radiation dose limits, and accreditation requirements of reporting radiologists..$^{53}$ Given these guidelines, together with recent advances in mammographic technology, we believe that there should be room for further local development of large-scale quality breast-screening programmes.

\section{Designing a screening programme for Hong Kong: can there be a protocol tailor-made for Chinese women?}

When planning a breast-screening programme, it is necessary to decide whom to screen (ie, at what age and the target screening population) and how to screen (ie, screening method).

For the decision of whom to screen, we should note that the mean age at diagnosis of breast cancer in Chinese women is 45 to 55 years, considerably younger than for western women. ${ }^{43}$ Starting screening at age 40 or 45 years would likely be a better fit for Chinese women than starting at age 50 years, as recommended by some western guidelines. As for the target screening population, current data favour universal screening over risk-based screening (pre-selecting patients according to risk profile). First, one should note that $80 \%$ of women with newly diagnosed breast cancer have no family history (ie, first-degree relative) or other significant previous risk factors, and therefore risk-based screening will miss a majority of screen-detected breast cancers. ${ }^{3,54}$ Second, a recent 10 -year populationbased cohort study of over 1.4 million asymptomatic Taiwanese women undergoing various breastcancer screening regimens showed that universal mammography screening based only on age and sex was more effective than other screening regimens (risk-based biennial mammography screening or annual $\mathrm{CBE}$ alone). ${ }^{49}$ In that study, universal biennial mammography screening was associated with a $41 \%$ reduction in mortality and a rate of 
overdiagnosis of only $13 \%$. In contrast, risk-based biennial mammography (pre-selecting patients according to risk profile or risk score) did not lead to any statistically significant reduction in mortality. Moreover, among all screening regimens, only universal biennial screening was associated with a clear downstaging shift in tumours (30\% reduction of stage $2+$ cancers), a crucial factor that can improve patient outcome. ${ }^{49}$

Regarding methods of screening, conventional screening uses standard two-view full-field digital (two-dimensional; 2D) mammography. Multiple studies have proven that screening by digital breast tomosynthesis (DBT; also called three-dimensional mammography) can increase cancer detection rates compared with 2D mammography alone, and can reduce the recall rate for benign findings (falsepositives)..$^{1,55} \mathrm{~A}$ retrospective analysis of over 454000 screens showed that use of DBT was associated with relative increases of $41 \%$ in invasive cancer detection, $49 \%$ in positive predictive value (PPV) for recall, and $21 \%$ in PPV for biopsy, in addition to a $15 \%$ reduction in the overall number of recalls. ${ }^{56} \mathrm{~A}$ recent meta-analysis by a Korean group also showed that screening with DBT increased detection of early invasive cancers of $<2 \mathrm{~cm} .{ }^{57}$ The American College of Radiology Commission on Breast Imaging now recommends that mammography and DBT are "usually appropriate" for screening of average-risk women, noting that DBT addresses some limitations of standard digital mammography. ${ }^{58}$ In Hong Kong, DBT has been increasingly adopted to replace or serve as an adjunct to 2D mammography in opportunistic screening. We anticipate that the shift to DBT screening will become a global trend.

The use of whole-breast ultrasonography to screen dense breasts is also commonly adopted in Asia, including for opportunistic screening in Hong Kong. In Japan, this practice was reinforced by a government-funded RCT (J-START) that studied the use of adjunctive ultrasonography to supplement mammography in screening over 70000 women. The J-START study showed favourable results of increased sensitivity and detection rate for early, preclinical cancers. ${ }^{41}$

Screening for high-risk women is often considered a separate entity. According to the American College of Radiology's Appropriateness Criteria, women at high risk due to prior mantle radiation between the ages of 10 and 30 years should start mammography 8 years after radiation therapy, but not before age 25 . For women with a genetic predisposition, annual screening mammography is recommended to begin 10 years earlier than the age that an affected relative had been diagnosed, but not before age 30 . Annual screening by magnetic resonance imaging is recommended in high-risk women as an adjunct to mammography. ${ }^{59}$

\section{Future directions for Hong Kong}

We believe that health care in Hong Kong should have the capability and expertise to roll out quality, large-scale population-screening programmes that are comparable to those in other developed Asian countries and cities. When we examine the common themes among available guidelines, literature, and expert reviews worldwide, the global trend is to provide women with an informed choice.

In the discussion of whether breast-cancer screening is feasible, one should bear in mind that this is an emotive issue. Apart from the critical appraisal of scientific evidence, the interpretation of literature and subsequent formulation of recommendations should always account for the socioeconomic, historical, and contextual realities. The value judgement of women should also be respected.

Frontline experts, including breast surgeons, oncologists, breast radiologists, and their representative professional associations should all participate in guideline panels, with a will to end the 'mammography wars'. Our Holy Grail should always be focused on improving cancer detection, reducing mortality, and improving patient outcome.

\section{References}

1. Eby PR. Evidence to support screening women annually. Radiol Clin North Am 2017;55:441-56.

2. Society of Breast Imaging Breast Screening Leadership Group. Screening in the 40-49 Age Group. Available from: https://www.sbi-online.org/RESOURCES/Breast ScreeningLeadershipGroupResources.aspx. Accessed 19 Nov 2017.

3. Ray KM, Price ER, Joe BN. Evidence to support screening women in their 40s. Radiol Clin North Am 2017;55:429-39.

4. The American College of Radiology. Guidelines for Breast Cancer Screening-An Update. SBI Breast Imaging Symposium 2016. Available from: https://www.sbi-online. org/Portals/0/Breast\%20Imaging\%20Symposium $\% 20$ 2016/Final\%20Presentations/4-7\%20800am\%20Smith\%20 - \% 20 Guidelines $\% 20$ for $\% 20$ Breast $\% 20$ Cancer $\% 20$ Screening.pdf. Accessed 19 Nov 2017.

5. Shieh Y, Eklund M, Sawaya GF, et al. Population-based screening for cancer: hope and hype. Nat Rev Clin Oncol 2016;13:550-65.

6. Byrne SK. What's the Buzz: Tell me what's happening in breast cancer screening. Asia Pac J Oncol Nurs 2017;4:1226.

7. Freer P, Moy L, DeMartini W; the Screening Leadership Group. Breast Cancer Screening: Understanding the Randomised Controlled Trials. Available from: https:// www.sbi-online.org/Portals/0/Screening\%20Leaders/ Breast $\% 20$ Cancer $\% 20$ Screening_Understanding $\% 20$ the $\% 20$ Randomized $\% 20$ Controlled $\% 20$ Trials.pdf. Accessed 19 Nov 2017.

8. Duffy SW, Chen TH, Smith RA, Yen AM, Tabar L. Real and artificial controversies in breast cancer screening. Breast Cancer Manage 2013;2:519-28.

9. Newell M, Eby PR; the Breast Screening Leadership 
Group. Benefits of Screening Mammography: Data from Population Service Screening. Available from: https:// www.sbi-online.org/Portals/0/Screening Leaders/Benefits of Screening Mammography_Data from Population Service Screening.pdf. Accessed 19 Nov 2017.

10. Miller AB, Baines CJ, To T, et al. Canadian National Breast Screening Study: 2. Breast cancer detection and death rates among women aged 50 to 59 years. CMAJ 1992;147:147788.

11. Miller AB, Baines CJ, To T, et al. Canadian National Breast Screening Study: 1. Breast cancer detection and death rates among women aged 40 to 49 years. CMAJ 1992;147:145976.

12. Miller AB, To T, Baines CJ, et al. Canadian National Breast Screening Study-2: 13-year results of a randomized trial in women aged 50-59 years. J Natl Cancer Inst 2000;92:14909.

13. Miller AB, To T, Baines CJ, et al. The Canadian National Breast Screening Study-1: breast cancer mortality after 11 to 16 years of follow-up. A randomized screening trial of mammography in women age 40 to 49 years. Ann Intern Med 2002;137:305-12.

14. Miller AB, Wall C, Baines CJ, et al. Twenty five year follow-up for breast cancer incidence and mortality of the Canadian National Breast Screening Study: randomised screening trial. BMJ 2014;348:g366.

15. Kopans DB, Feig SA. The Canadian National Breast Screening Study: a critical review. AJR Am J Roentgenol 1993;161:755-60.

16. Burhenne LJ, Burhenne HJ. The Canadian National Breast Screening Study: a Canadian critique. AJR Am J Roentgenol 1993;161:761-3.

17. Kopans D. Breast Imaging. 3rd ed. Lippincott Williams \& Wilkins: Philadelphia; 2007.

18. Heywang-Köbrunner SH, Schreer I, Hacker A, et al. Conclusions for mammography screening after 25-year follow-up of the Canadian National Breast Cancer Screening Study (CNBSS). Eur Radiol 2016;26:342-50.

19. Boyd NF. The review of randomization in the Canadian National Breast Screening Study. Is the debate over? CMAJ 1997;156:207-9.

20. Baines CJ, Miller AB, Kopans DB, et al. Canadian National Breast Screening Study: assessment of technical quality by external review. AJR Am J Roentgenol 1990;155:743-7; discussion 8-9.

21. International Agency for Cancer on Research (IARC), World Health Organization. IARC Handbooks of Cancer Prevention. Volume 7: Breast Cancer Screening. IARC Press; 2002. Available from: http://www.iarc.fr/en/ publications/pdfs-online/prev/handbook7/Handbook7_ Breast-4.pdf. Accessed 15 Mar 2018.

22. Gotzsche PC, Olsen O. Is screening for breast cancer with mammography justifiable? Lancet 2000;355:129-34.

23. Tabár L, Dean PB, Cen TH, et al. The impact of mammography screening on the diagnosis and management of early-phase breast cancer. In: Francescatti D, Silverstein M, editors. Breast Cancer: A New Era in Management. Springer New York; 2014: 31-78.

24. Bock K, Borisch B, Cawson J, et al. Effect of populationbased screening on breast cancer mortality. Lancet 2011;378:1775-6.

25. Patnick J, Perry N, de Wolf C. Effect of population-based screening on breast cancer mortality-Authors' reply.
Lancet 2012;379:1298

26. Mcneil DG. Confronting cancer: scientist at workPeter Gotzsche; A career that bristles with against-thegrain conclusions. Available from: http://www.nytimes. com/2002/04/09/science/confronting-cancer-scientistwork-peter-gotzsche-career-that-bristles-with.html. Accessed 19 Nov 2017.

27. Cuzick J. Breast cancer screening-time to move forward. Lancet 2012;379:1289-90.

28. Chiolero A, Rodondi N. Lessons from the Swiss Medical Board recommendation against mammography screening programs. JAMA Intern Med 2014;174:1541-2.

29. Biller-Andorno N, Juni P. Abolishing mammography screening programs? A view from the Swiss Medical Board. N Engl J Med 2014;370:1965-7.

30. Helvie MA, Chang JT, Hendrick RE, et al. Reduction in late-stage breast cancer incidence in the mammography era: Implications for overdiagnosis of invasive cancer. Cancer 2014;120:2649-56.

31. Kopans DB, Smith RA, Duffy SW. Mammographic screening and "overdiagnosis". Radiology 2011;260:61620.

32. Puliti D, Duffy SW, Miccinesi G, et al. Overdiagnosis in mammographic screening for breast cancer in Europe: a literature review. J Med Screen 2012;19 Suppl 1:42-56.

33. Duffy SW, Agbaje O, Tabar L, et al. Overdiagnosis and overtreatment of breast cancer: estimates of overdiagnosis from two trials of mammographic screening for breast cancer. Breast Cancer Res 2005;7:258-65.

34. Bleyer A, Welch HG. Effect of three decades of screening mammography on breast-cancer incidence. N Engl J Med 2012;367:1998-2005.

35. Duffy SW, Dibden A, Michalopoulos D, et al. Screen detection of ductal carcinoma in situ and subsequent incidence of invasive interval breast cancers: a retrospective population-based study. Lancet Oncol 2016;17:109-14.

36. Tosteson AN, Fryback DG, Hammond CS, et al. Consequences of false-positive screening mammograms. JAMA Intern Med 2014;174:954-61.

37. Schwartz LM, Woloshin S, Fowler FJ, Jr, et al. Enthusiasm for cancer screening in the United States. JAMA 2004;291:71-8.

38. Kopans DB. An open letter to panels that are deciding guidelines for breast cancer screening. Breast Cancer Res Treat 2015;151:19-25.

39. Duffy SW, Chen TH, Smith RA, Yen AM, Tabar L. Real and artificial controversies in breast cancer screening. Breast Cancer Manage 2013;2:519-28.

40. Montero AJ, Eapen S, Gorin B, et al. The economic burden of metastatic breast cancer: a U.S. managed care perspective. Breast Cancer Res Treat 2012;134:815-22.

41. Ohuchi N, Ishida T, Kawai M, et al. Randomized controlled trial on effectiveness of ultrasonography screening for breast cancer in women aged 40-49 (J-START): research design. Jpn J Clin Oncol 2011;41:275-7.

42. Sung H, Rosenberg PS, Chen WQ, et al. Female breast cancer incidence among Asian and Western populations: more similar than expected. J Natl Cancer Inst 2015;107.

43. Fan L, Strasser-Weippl K, Li JJ, et al. Breast cancer in China. Lancet Oncol 2014;15:e279-89.

44. Youlden DR, Cramb SM, Yip CH, et al. Incidence and mortality of female breast cancer in the Asia-Pacific region. Cancer Biol Med 2014;11:101-15. 
45. Singapore Health Promotion Board. National Registry of Diseases Office. Singapore Cancer Registry Interim Annual Report: Trends in cancer incidence in Singapore 2010-2014. Available from: https://www.nrdo.gov.sg/ docs/librariesprovider3/default-document-library/ cancer-trends-2010-2014_interim-annual-report_final\%28public\%29.pdf?sfvrsn=0. Accessed 19 Nov 2017.

46. Hospital Authority, Hong Kong. Hong Kong Cancer Registry. Available from: http://www3.ha.org.hk/ cancereg/. Accessed 19 Mar 2018.

47. Leung GM, Thach TQ, Lam TH, et al. Trends in breast cancer incidence in Hong Kong between 1973 and 1999: an age-period-cohort analysis. Br J Cancer 2002;87:982-8.

48. Breast cancer in Asia-The Challenge and Response. A Report from the Economist Intelligence Unit. Available from: https://www.eiuperspectives.economist.com/sites/ default/files/EIU Breast Cancer in Asia_Final.pdf. Accessed 19 Nov 2017.

49. Yen AM, Tsau HS, Fann JC, et al. Population-based breast cancer screening with risk-based and universal mammography screening compared with clinical breast examination: a propensity score analysis of 1429890 Taiwanese women. JAMA Oncol 2016;2:915-21.

50. Song QK, Wang XL, Zhou XN, et al. Breast cancer challenges and screening in China: lessons from current registry data and population screening studies. Oncologist 2015;20:773-9.

51. A Hong Kong Breast Cancer Foundation Initiative. Hong Kong Breast Cancer Registry Report No. 8, 2016. Available from: http://www.hkbcf.org/download/bcr_report8/hkbcf_ report_2016_full_report.pdf. Accessed 19 Nov 2017.
52. Lui CY, Lam HS, Chan LK, et al. Opportunistic breast cancer screening in Hong Kong; a revisit of the Kwong Wah Hospital experience. Hong Kong Med J 2007;13:10613.

53. Hong Kong College of Radiologists Mammography Statement. Available from: https://www.hkcr.org/ templates/OS03C00336/case/lop/HKCR Mammography Statement_rev20150825.pdf. Accessed 19 Nov 2017.

54. Destounis SV, Arieno AL, Morgan RC, et al. Comparison of breast cancers diagnosed in screening patients in their 40s with and without family history of breast cancer in a community outpatient facility. AJR Am J Roentgenol 2014;202:928-32.

55. Rafferty EA, Rose SL, Miller DP, et al. Effect of age on breast cancer screening using tomosynthesis in combination with digital mammography. Breast Cancer Res Treat 2017;164:659-66.

56. Friedewald SM, Rafferty EA, Rose SL, et al. Breast cancer screening using tomosynthesis in combination with digital mammography. JAMA 2014;311:2499-507.

57. Yun SJ, Ryu CW, Rhee SJ, et al. Benefit of adding digital breast tomosynthesis to digital mammography for breast cancer screening focused on cancer characteristics: a meta-analysis. Breast Cancer Res Treat 2017;164:557-69.

58. Monticciolo DL, Newell MS, Hendrick RE, et al. Breast cancer screening for average-risk women: recommendations from the ACR commission on breast imaging. J Am Coll Radiol 2017;14:1137-43.

59. Expert Panel on Breast Imaging; Mainiero MB, Moy L, Baron P, et al. ACR Appropriateness Criteria Breast Cancer Screening. J Am Coll Radiol 2017;14:S383-90. 